\title{
The Simulation and Research of Steel-Work Construction Based on Fuzor
}

\author{
Chen Dong ${ }^{1}$, Ding Shaopeng ${ }^{2}$ Chen Ming $^{3}$, and Shao Chenyue ${ }^{4}$ \\ ${ }^{1}$ School of civil engineering, Anhui Jianzhu University, Anhui Hefei, 230601, China \\ ${ }^{2}$ School of civil engineering, Anhui Jianzhu University, Anhui Hefei, 230601, China \\ ${ }^{3}$ School of civil engineering, Anhui Jianzhu University, Anhui Hefei, 230601, China \\ ${ }^{4}$ School of civil engineering, Anhui Jianzhu University, Anhui Hefei, 230601, China
}

\begin{abstract}
BIM can achieve analogue simulate the real information of buildings through digital information, aiming to find engineering problems in advance, correct errors timely and reduce waste. At present, BIM has been widely used in the design and construction stage of the construction industry. As a plug-in of AutodeskRevit, Fuzor software can find the problems in the design and construction more intuitive and real, and synchronize the changes. In this massage, the author will take the construction simulation application of 11\#experimental building in Fuzor as an example to study the application of Fuzor in constructional engineering.
\end{abstract}

\section{Introduction}

The development of science and technology is changing our working ways and improving our working efficiency. The application of BIM in construction engineering is one of them. Building Information Model (BIM) can parametrically edit all engineering information of construction project including geometric information, and build a three-dimensional building model of the project. Through the way of three-dimensional simulation, the feasibility of the project scheme can be visually analyzed in designing and early stage of constructing, and the structural layout of the project can be modified, which not only ensures the quality of the project, but also improves the working efficiency of this project, further shorten the cycle of construction.

Fuzor is a plug-in of virtual reality on AutodeskRevit, an application software of BIM. It is simple and convenient to operate and does not need foundation of art. It can simulate real environment through computer and provide users with simulation of vision, hearing, touch and other senses. Therefore, users can observe things in threedimensional like they are in the environment and optimize three-dimensional things through his own experience.

\section{Main functions of Fuzor}

Fuzor is a technical platform that combines VR with 4D construction simulation technology. It has powerful functions. In order to realize the virtual reality of building model conveniently and quickly ${ }^{[1]}$, Fuzor plug-in has the following three characteristics:

(1) bidirectional: as a plug-in of Revit, Fuzor can be perfectly compatible with Revit models. With one of Fuzor and Revit, the parameter adjustment of the model will be updated to the other party in real time. This function synchronizes the changes between models perfectly.

(2) Analyticity: Fuzor not only can update, modify and view the model in real time with Revit without exporting the model, but also has the same functions as NavisWorks to carry out collision detection among various disciplines in the model and export the collision detection report.

(3) Simulation: Fuzor can also edit the animation of the simulated building, and its picture's authenticity is the same as Lumion's effect. It has powerful rendering function, and its product cost is low, operation is simple, simulation speed is much fast, it can help users to improve working efficiency, and product the video works they want with the lowest cost ${ }^{[2]}$.

The application of Fuzor in designing enables designers to predict and modify the errors encountered in the design ahead of schedule through collision detection before construction, so as to improve the design quality; in the construction stage, the on-site construction personnel and safety supervisors can carry out on-site construction by comparing the construction information of the building model, improving the construction quality and efficiency, and reduce the waste of manpower and material resources which caused by construction ${ }^{[3]}$. 


\section{Application of Fuzor Steel Structure Simulating Construction Process in Project}

\subsection{Project Overview}

The overall floorage of this project is about 138,900 $\mathrm{m}^{2}$, and 14 departments in total, including scientific research building, academic exchange center, living infrastructures, international talent apartment, user's facility, scientist studio, research experimental plant, people's air defense, and parking lot, and special power, special water, conventional heating, and road, and other public supporting facilities served for scientific installation service. The steel structure mainly involves the following departments, which are $4 \#$ complex building, 7\# laboratory building, 10\# laboratory building, 11\# laboratory building, 12\# laboratory building, 13\# laboratory building, and corridor (refers to the fig.1).

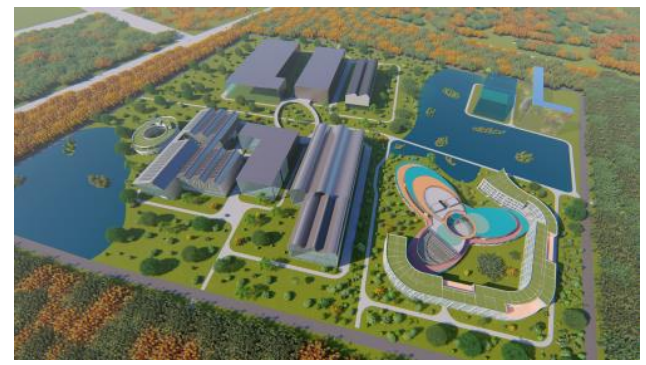

Fig. 1 the layout

With long spans and large space, the construction of steel structure is complex, in high insallation accuracy, and large hoisting difficulty, by means of Fuzor plug-in, the designer can find the problems in the process of construction fast by means of the making of the process of construction animation of the steel structure, so that the designer can consistently improve the process of construction. The process of the engineering construction includes civil engineering surrender face, civil engineering survey, components into factory and inspection submission, supporting and hoisting of steel balls and among them, hoisting of crane beam, horizontal supporting and hoisting, high altitude rack in bulk, interlining hoisting of steel frame, roofing maintenance system installation, and wall maintenance system installation, and etc ${ }^{[4]}$. These series of processes are easy to operate and fast to deduce by means of the virtual reality environment provided by Fuzor plug-in.

\subsection{Making and Outputting of Construction Animation by Fuzor}

Select the Revit model in 11\# laboratory building, click OK to print it into Fuzor, which can refer to fig. 2. The designer can construct virtual reality environment by means of Fuzor plug-in, find the faults in the model and mark them, and then have modification on them after the revision on the model.

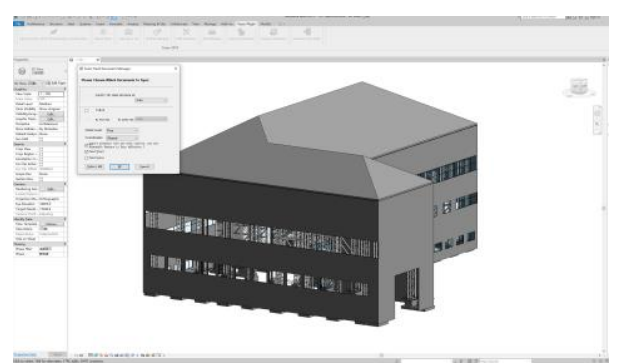

Fig. 2Synchronous emulation pic

After confirmation, the making and outputting of construction animation can be operated, and the main steps are as follows:

(1) After the entrance of Fuzor, click 4D simulation, then it can enter into the interface, and the construction process bar can be activated by means of the setting on the start time and end time of task (as fig. 3)

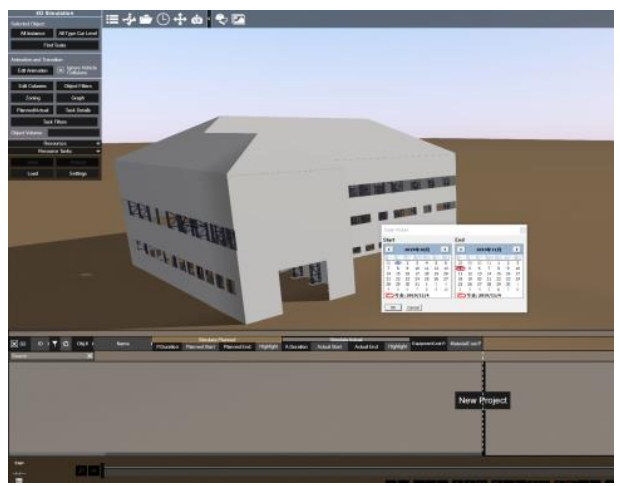

Fig. 3 Synchronous emulation pic

(2) It can set up tasks in accordance with the types of different tasks, mainly including growth task, mechanical task, demolition task, temporary task, and periodic task (as fig. 4). In accordance with the construction procedure and chronological order of 11 \# laboratory building, it can establish related tasks.

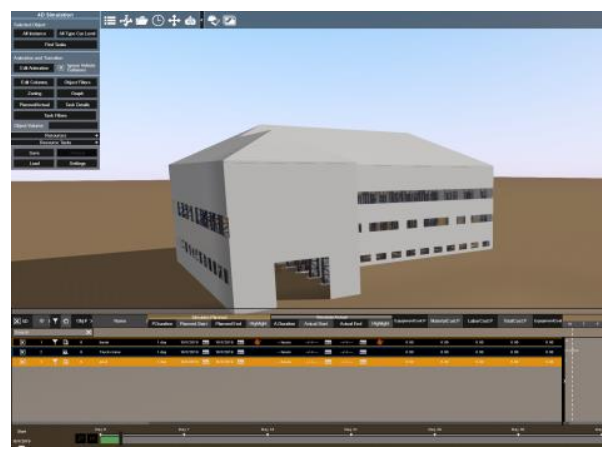

Fig. 4 Establish construction tasks

(3) In accordance with the required machinery in the process of construction, it can make the mechanical animation, and clicking material depot, it can find required construction equipment. As to this project, it mainly takes steel structure as main body, and has hoisting of steel structure by means of crane truck. After finding crane truck in the material depot, add it into project, by means of adding keyframe and adjusting construction animation 
in the properties menu, it can become a continuous animation (as fig. 5), and then it can be added into the project.
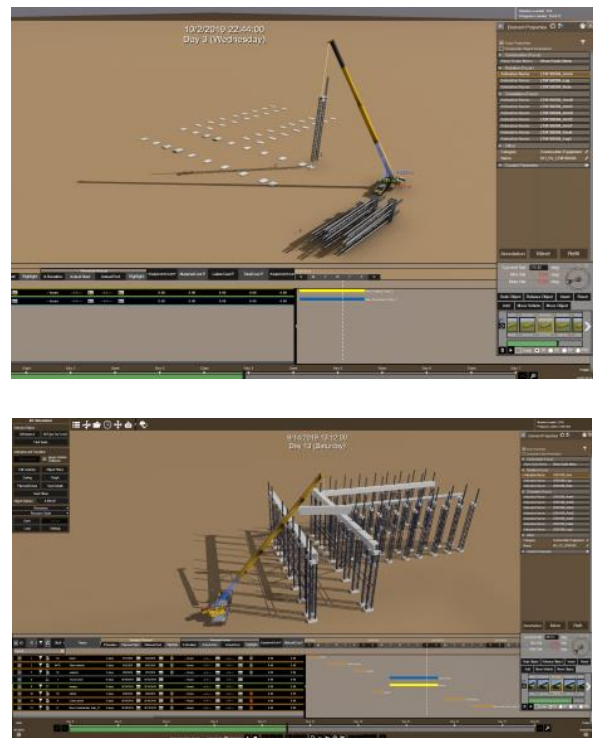

Fig. 5 Mechanical construction animation

(4) Create all tasks in order and then click viewpoint animation. The number of viewpoints depends on the complexity and importance of the task. So that the animation can be very coherent and precise. Click play to check whether the created task has any errors after completed. After confirmation, finally click rendering and output the video like fig. $6 \& 7$.

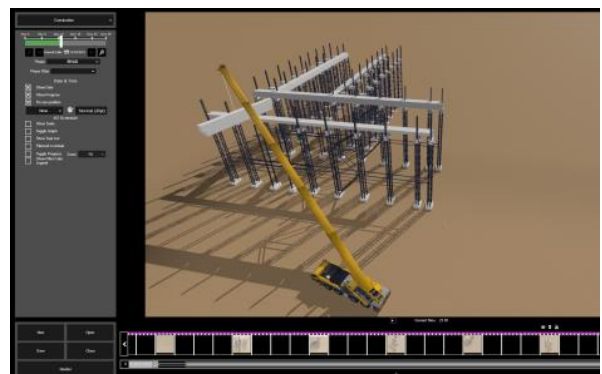

Fig. 6 Add viewpoint

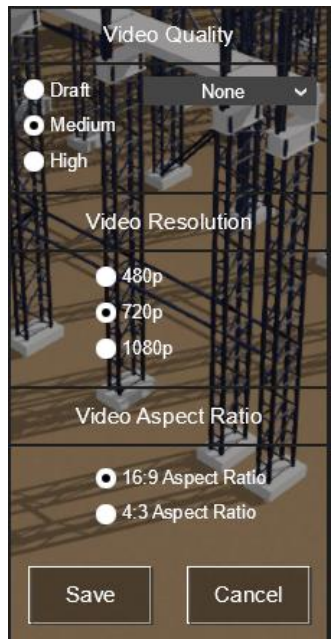

Fig. 7 Video output

\section{Conclusion}

BIM animation can show the principle and characteristics of technological innovation more intuitively and vividly, it plays an important role in the future development of the construction industry. Now, Fuzor technology is still under exploration and few people can master its application, steel structure construction animation mentioned above is only one of its applications. There are still many functions to be developed and applied. Real time exchange between fuzor plug-in and autodeskrevit software is conducive to the development of Construction Engineering. Also, continue developing new application of Fuzor would promote modernization of construction industry ${ }^{[5]}$.

\section{Acknowledgments}

This research was financially supported by Natural Science Foundation of Anhui Province(1908085ME173), National key R \& D projects (2016YFC0701700)

\section{References}

1. Sun Yuchen, Chen Qingyuan, Zhou Jiangxiang. Application of fuzor technology in construction projects $[\mathrm{J}]$. Technology and application. 2: 73-75, (2016)

2. Bai Xuehai, $\mathrm{Xu}$ Zhen. Virtual, experience and interaction - the comprehensive application of fuzor in the teaching of architectural design. See: Architectural Digital Technology Teaching Committee of the National Steering Committee of architectural discipline, School of architecture and urban planning, Huazhong University of science and technology. Digital construction culture 2015 national architectural digital technology teaching seminar proceedings. Beijiiung: China's construction industry Press, 71-75, (2015)

3. Gao Yun. Development and Enlightenment of virtual technology -- Taking Microsoft's hololens as an example [J]. Internet economy,12:50-55,(2017)

4. Li Pingyan. Key construction points and quality control of steel structure industrial plant $[\mathrm{J}]$. Jushe, 30:63, (2018)

5. pan Xing, Liu Yun. Application of BIM + fuzor technology in construction industry $[\mathrm{J}]$. Focus on information.6:89-92, (2019) 